\title{
Interpretationof Simple and Distributive Ideals of 1-nearSemilattice
}

\author{
Sri Rama Ravi Kumar.E \\ V.R.Siddhartha Engineering College, Vijayawada, India -520 007 \\ Venkateswara Rao.J \\ Department of Mathematics, CNCS, P.O.Box No: 231, Mekelle University Main Campus \\ Mekelle, Ethiopia \\ Sri Sivaji.V \\ K.L.University,Vadeswaram,Guntur,India
}

\begin{abstract}
This paper initiates the notion of simple elements in l-near semilattice and identifies several characterizations of these elements. In addition, it is detected that an element is a simple if and only if it is both modular and distributive in semilattice. Further, it is noticed that there are various portrayals of distributive and simple ideals of l-near semilattice. Characterization theorem for simple ideal in a l-near semilattice is established and also determined a necessary and sufficient condition for a distributive ideal to be a simple ideal in a l-near semilattice.
\end{abstract}

Keywords - :Semilattice, modular ideal, simple ideal and distributive ideal.

AMS 2010 Mathematics Classification numbers: 06A12,06C05,06D10,06B10.

\section{INTRODUCTION}

The concepts of distributive ideal, standard ideal and neutral ideal in lattice have been introduced and studied by Gratzer,G and Schmidt,E.T [1] in 1961. Ramana Murthy, P.V and Ramam,V. [4] observed the permutability of distributive congruence relations in join semilattice directed below in 1985. Then, Malliab,C and Bhatta,S.P. A [3] obtained the generalization of distributive ideals to convex sublattice in 1986. VasanthaKandasamy W.B. [5] attained a new type of product on lattice-Near semilattice in 1993. Further, Hossian,M. A.[2] noticed the distributive filters of a meet semilattice directed above in 2004.

Let $\mathrm{L}$ be a lattice with 0 and 1 . The product defined on $\mathrm{L} \mathrm{X}_{\mathrm{p}} \mathrm{L}$ is as follows.For $\left(\mathrm{a}_{1}, \mathrm{~b}_{1}\right),(\mathrm{a}, \mathrm{b}) \in \mathrm{L} \mathrm{X}_{\mathrm{p}} \mathrm{L}$ we define $\left(a_{1}, b_{1}\right) \cup(a, b)=\left(a_{1} \cup a, b_{1} \cup b\right)$ and $\left(a_{1}, b_{1}\right) \cap(a, b)=\left(a_{1} \cap a, b_{1} \cap b\right)$. We refer $(0,0)$ be the smallest element and $(1,1)$ be the largest element of $L X_{p} L$. $\left(L X_{p} L, U\right)$ and $\left(L X_{p} L, \cap\right)$ are called the near semilattices. A near lattice is usually defined as a meet semilattice in which every initial segment is a lattice. That is, it is a semilattice possessing the upper bound property. A poset in which every initial segment is a join semilattice is a near semilattice in a structure.

In this document we describe 1-near semilattice and establish a characterization theorem for simple ideal in a 1-near semilattice. Also we have prearranged a necessary and sufficient condition for a distributive ideal to be a simple ideal in a 1- near semilattice.

\section{Section 1}

1.1 Definition: An 1-near semi lattice is a join semi lattice possessing the lower bound property. That is, every pair of elements having lower bound has a greatest lower bound.

1.2 Example: Let $\mathrm{S}=\{1,2,3,6 ; /\}$ be a poset under divisibility. Then $1 \mathrm{~cm}(1,2)=2,1 \mathrm{~cm}(2,3)=6,1 \mathrm{~cm}(2,6)=$ 6.Similarly we can obtain $1 \mathrm{~cm}$ (least common multiple, $\mathrm{aV} b=1 \mathrm{~cm}\{\mathrm{a}, \mathrm{b}\}$ for $\mathrm{a}, \mathrm{b} \in \mathrm{S}$ ) of all elements of $\mathrm{S}$.

1.3. Definition: A l-near semi lattice $S$ is said to be modular if, for all $\mathrm{x}, \mathrm{y}, \mathrm{z} \in \mathrm{S}$ with $\mathrm{z} \leq \mathrm{x} \leq \mathrm{y} \vee \mathrm{z}$, then there exists $\mathrm{y}_{1}$, a lower bound of $\mathrm{y}$ in $\mathrm{S}$ such that $\mathrm{x}=\mathrm{y}_{1} \vee \mathrm{z}$.

1.4. Definition: An element $\mathrm{s}$ of a l-near semi lattice $\mathrm{S}$ is called a simple element, if $\mathrm{x} \leq \mathrm{s} V \mathrm{t}$ for $\mathrm{x}, \mathrm{t}$ in $\mathrm{S}$, then their exists $s_{1}$ and $t_{1}$ as lower bounds of $s$ and $t$ respectively in $S$ such that

$\mathrm{x}=\mathrm{s}_{1} \vee \mathrm{t}_{1}$.

1.5. Example: In a bounded semi lattice [0,1], the elements 0 and 1 are simple elements.

1.6. Definition: An element $\mathrm{m}$ of a 1- near semi lattice $\mathrm{S}$ is called modular element if 
$\mathrm{x} \leq \mathrm{m} \vee \mathrm{y}$ with $\mathrm{y} \leq \mathrm{x}$ for $\mathrm{x}, \mathrm{y}$ in $\mathrm{S}$, then their exists $\mathrm{m}_{1}$ as lower bound of $\mathrm{m}$ in $\mathrm{S}$ such that $\mathrm{x}=\mathrm{m}_{1} \mathrm{\vee y}$.

1.7. Example: Let $\mathrm{S}=\{1,2,3,6\}$ be a near semi lattice with $\mathrm{x} \leq \mathrm{y}$ (which means that $\mathrm{x}$ divides $\mathrm{y}$ ). Define $\mathrm{aV} \mathrm{b}=$ $1 \mathrm{~cm}\{\mathrm{a}, \mathrm{b}\}$. The elements $1,2,3,6$ are all modular elements of $\mathrm{S}$ as shown in figure:

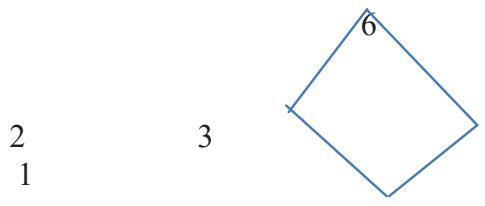

Fig 1. Showing 1 as a modular element

Because $2 \leq 1 \vee 2$ with $2 \leq 2$, then 1 is a lower bound of 2 such that $2=1 \mathrm{~V} 2$. Therefore 1 is modular element.

1.8. Definition: A non empty subset $\mathrm{I}$ of l-near semi lattice $\mathrm{S}$ is called an ideal of $\mathrm{S}$ if (i) for $\mathrm{x}, \mathrm{y}$ in $\mathrm{I}, \mathrm{x} \vee \mathrm{y} \in \mathrm{I}$, provided $\mathrm{x} V \mathrm{y}$ exists (ii) for $\mathrm{x}$ in $\mathrm{I}, \mathrm{t} \leq \mathrm{x}$ for $\mathrm{t}$ in $\mathrm{S}$ implies $\mathrm{t} \in \mathrm{I}$.

1. 9. Definition: An ideal $\mathrm{I}$ of an l-near semi lattice $\mathrm{S}$ is a simple ideal if $\mathrm{X} \vee(\mathrm{I} \wedge \mathrm{Y}) \leq(\mathrm{X} \vee \mathrm{I}) \wedge(\mathrm{X} \vee \mathrm{Y})$ where $\mathrm{X}$ and $\mathrm{Y}$ are ideals of $\mathrm{S}$.

1.10.Definition: An ideal $\mathrm{M}$ of al-near semi lattice $\mathrm{S}$ is said to be modular in which every element is modular. 1.11. Definition: An element $\mathrm{d}$ of a l- near semi lattice $\mathrm{S}$ is called distributive if $\mathrm{x} \leq \mathrm{d} \vee \mathrm{a}$ and $\mathrm{x} \leq \mathrm{d} \vee \mathrm{b}$ for $\mathrm{x}, \mathrm{a}, \mathrm{b}$ in $\mathrm{S}$. Then there exists a lower bound $\mathrm{c}$ of $\mathrm{a}$ and $\mathrm{b}$ in $\mathrm{S}$ such that $\mathrm{x} \leq \mathrm{d} \vee \mathrm{c}$.

1. 12. Example: Every simple element is a distributive element.

1. 13. Note: Every element of a modular l-near semi lattice is modular. If every element of al-near semi lattice is modular, then it is a modular 1-near semi lattice.

1. 14. Theorem: An element $\mathrm{m}$ of 1 -near semi lattice $\mathrm{S}$ is modular if and only if $(\mathrm{m}]$ is modular ideal of $\mathrm{S}$.

Proof: Let $\mathrm{m}$ be a modular element of a l-near semi lattice $\mathrm{S}$. Then for $\mathrm{x}, \mathrm{y}$ in $\mathrm{S}, \mathrm{x} \leq \mathrm{mV} \mathrm{y}$ with $\mathrm{y} \leq \mathrm{x}$ for $\mathrm{x}, \mathrm{y}$ in $\mathrm{S}$. So there exists $\mathrm{m}_{1}$, a lower bound of $\min \mathrm{S}$ such that $\mathrm{x}=\mathrm{m}_{1} \vee \mathrm{y}$. Let $(\mathrm{m}]$ be a non empty subset of $\mathrm{S}$.

Then (i) for $\mathrm{x}_{1}, \mathrm{y}_{1} \in(\mathrm{m}], \mathrm{x}_{1} \leq \mathrm{m}, \mathrm{y}_{1} \leq \mathrm{m}$, implies $\mathrm{x}_{1} \vee \mathrm{y}_{1} \leq \mathrm{m}$. Thus, $\mathrm{x}_{1} \vee \mathrm{y}_{1} \in(\mathrm{m}]$.

(ii) For $\mathrm{x} \in(\mathrm{m}]$ and for $\mathrm{t} \in \mathrm{S}$ with $\mathrm{t} \leq \mathrm{x}$, as $\mathrm{x} \leq \mathrm{m}$, where $\mathrm{t} \leq \mathrm{x}$, we have $\mathrm{t} \leq \mathrm{x} \leq \mathrm{m}$, implies that $\mathrm{t} \in(\mathrm{m}]$. Thus (m) is a ideal of $\mathrm{S}$.

To prove that $(\mathrm{m}]$ is a modular ideal of $\mathrm{S}$. Let $\mathrm{x} \leq \mathrm{m} \vee \mathrm{y}$ with $\mathrm{y} \leq \mathrm{x}$ for $\mathrm{m} \in(\mathrm{m}]$ and $\mathrm{x}, \mathrm{y} \in \mathrm{S}$. Thus $\mathrm{m}_{1}$ is a lower bound of $\mathrm{m} \in(\mathrm{m}] \subseteq \mathrm{S}$. So that $\mathrm{x}=\mathrm{m}_{1} \vee \mathrm{y}$. Hence $(\mathrm{m}]$ is modular ideal of $\mathrm{S}$. Conversely, suppose $(\mathrm{m}]$ is a modular ideal of $\mathrm{S}$. Then, for $\mathrm{m} \in(\mathrm{m}] \subseteq \mathrm{S}$, if $\mathrm{x} \leq \mathrm{mV}$ y with

$\mathrm{y} \leq \mathrm{x}$. Then there is a lower bound $\mathrm{m}_{1}$ of $\mathrm{m} \in(\mathrm{m}]$ such that $\mathrm{x}=\mathrm{m}_{1} \vee \mathrm{y}$. Therefore $\mathrm{m} \in \mathrm{S}$ is a modular element.

1.15. Theorem: Every simple element of 1-near semi lattice $\mathrm{S}$ is a distributive element of $\mathrm{S}$.

Proof: Let $\mathrm{s}$ be a simple element of al-near semi lattice $\mathrm{S}$. Suppose $\mathrm{x} \leq \mathrm{s} \vee \mathrm{a}, \mathrm{x} \leq \mathrm{s} \vee \mathrm{b}$ for $\mathrm{a}, \mathrm{b}$ and $\mathrm{x} \in \mathrm{S}$. Since $\mathrm{s}$ is simple element, there exists $s_{1}$ a lower bound of $\sin S$ and $a_{1}$ as lower bound of a in $S$ such that $x=s_{1} \vee a_{1}$. Now for $\mathrm{a}_{1} \leq \mathrm{x} \leq \mathrm{s} \vee \mathrm{b}$, we have $\mathrm{a}_{1} \leq \mathrm{s} \vee \mathrm{b}$, where $\mathrm{s}$ is simple element. Then there exists $\mathrm{s}_{2}$, a lower bound of $\sin$ $\mathrm{S}$ and $\mathrm{b}_{2}$, a lower bound of $\mathrm{b}$ such that $\mathrm{a}_{1}=\mathrm{s}_{2} \vee \mathrm{b}_{2}$. Therefore for $\mathrm{x}=\mathrm{s}_{1} \vee \mathrm{a}_{1}=\mathrm{s}_{1} \vee \mathrm{s}_{2} \vee \mathrm{b}_{2} \leq \mathrm{s} \vee \mathrm{b}_{2}$ as $\mathrm{s}_{1}$ and $\mathrm{s}_{2}$ are lower bounds of $\mathrm{s}$ in $\mathrm{S}$. Thus $\mathrm{b}_{2} \leq \mathrm{a}_{1} \leq \mathrm{a}$ and $\mathrm{b}_{2} \leq \mathrm{b}$. Hence, $\mathrm{b}_{2}$ is lower bound of a and $\mathrm{b}$ such that $\mathrm{x} \leq \mathrm{sV} \mathrm{b}_{2}$. Therefore $\mathrm{s}$ is a distributive element of $\mathrm{S}$.

1.16. Theorem: Let $s_{1}$ and $s_{2}$ be a simple element of 1- near semi lattice $S$. Then $s_{1} V s_{2}$ is also a simple element of $\mathrm{S}$.

Proof: Let $\mathrm{s}_{1}$ and $\mathrm{s}_{2}$ be simple elements of a l-near semi lattice $\mathrm{S}$.

Then for $\mathrm{x} \leq\left(\mathrm{s}_{1} \vee \mathrm{s}_{2}\right) \vee \mathrm{t}=\mathrm{s}_{1} \vee\left(\mathrm{s}_{2} \vee \mathrm{t}\right)$ as $\mathrm{s}_{1}$ is a simple element, there exists a lower bound a of $\mathrm{s}_{1}$ and a lower bound $b$ of $s_{2} \vee t$ in $S$ such that $x=a \vee b$. Since $b \leq s_{2} \vee t$ and $s_{2}$ a simple element, then there exists a lower bound $\mathrm{c}$ of $\mathrm{s}_{2}$ and a lower bound $\mathrm{d}$ of $\mathrm{t}$ such that $\mathrm{b}=\mathrm{cV} \mathrm{d}$.

Therefore for $\mathrm{x}=\mathrm{a} \vee \mathrm{b}=\mathrm{aVc \vee} \mathrm{d}$ for $\mathrm{a} \leq \mathrm{s}_{1}, \mathrm{c} \leq \mathrm{s}_{2}$ and $\mathrm{d} \leq \mathrm{t}$. Thus $\mathrm{a} \vee \mathrm{c} \leq \mathrm{s}_{1} \vee \mathrm{s}_{2}, \mathrm{~d} \leq \mathrm{t}$. Hence, for $\mathrm{x} \leq\left(\mathrm{s}_{1} \vee \mathrm{s}_{2}\right) \vee \mathrm{t}$, $a \vee c$ is a lower bound of $\left(s_{1} \vee s_{2}\right)$ and $d$ is a lower bound of $t$ in $S$, such that $x=(a \vee c) \vee d$. Hence $s_{1} \vee s_{2}$ is also a simple element.

1.17. Theorem: An ideal $\mathrm{T}$ of a 1-near semi lattice $\mathrm{S}$ satisfies relation,

$\mathrm{IV}(\mathrm{T} \wedge \mathrm{J}) \leq(\mathrm{IVT}) \wedge(\mathrm{IVJ})$ where, $\mathrm{I}$ and $\mathrm{J}$ are ideals of $\mathrm{S}$ is a simple if and only if there holds the condition that $\mathrm{x} \leq$ $t \vee a$, and then, there exists $t_{1}$ and $a_{1}$ lower bounds of $t$ and a respectively in $S$ such that $x=t_{1} \vee a_{1}$, for $t \in T$ and $\mathrm{a} \in \mathrm{J}$. 
Proof: Let an ideal $\mathrm{T}$ is simple, satisfies the relation $(\mathrm{x}] \vee(\mathrm{T} \wedge(\mathrm{a}]) \leq((\mathrm{x}] \vee \mathrm{T}) \wedge((\mathrm{x} \vee(\mathrm{a}])$ for $(\mathrm{x}]$ and (a] are ideals of $\mathrm{S}$. Thus for $\mathrm{x} \in(\mathrm{x}] \vee(\mathrm{T} \wedge(\mathrm{a}]) \leq((\mathrm{x}] \vee \mathrm{T}) \wedge((\mathrm{x} \vee(\mathrm{a}])$,

Implies $x \in((x] \vee T)$ and $x \in((x \vee(a])$.

This implies $\mathrm{x} \leq \mathrm{t} \vee$ a for $\mathrm{a} \in(\mathrm{x}]$ and $\mathrm{x} \leq \mathrm{t}_{1} \vee \mathrm{a}_{1}$ for $\mathrm{t}_{1} \in(\mathrm{x}]$ and $\mathrm{a}_{1} \in(\mathrm{a}]$.

This indicates, $x \leq t \vee$ a and $x \leq t_{1} \vee a_{1}$ for $a \leq x, t_{1} \leq x$ and $a_{1} \leq a$, which implies $x \leq t_{1} \vee a_{1}$ for $a_{1} \leq a \leq x$ and $t_{1}$ $\leq \mathrm{x}$. Then it follows that $\mathrm{x} \leq \mathrm{t}_{1} \vee \mathrm{a}_{1}, \mathrm{t}_{1} \vee \mathrm{a}_{1} \leq \mathrm{x}$. Hence, $\mathrm{x}=\mathrm{t}_{1} \vee \mathrm{a}_{1}$. Therefore, an ideal $\mathrm{T}$ is simple if it satisfies the given condition.

Suppose that an ideal T satisfies, $\mathrm{x} \leq \mathrm{tV}$ a.

Then there exists $t_{1}$ and $a_{1}$ are lower bounds of $t$ and $a$ in $S$ such that $x=t_{1} \vee a_{1}$.

Now to show that the respective condition satisfies.

Let $x \in(I \vee(T \wedge J))$, then $x \leq i \vee s$ for $s \in(T \wedge J)$. Then for $x \leq i \vee s, i_{1}$ and $s_{1}$ are lower bounds of $i$ and $\sin S$ such that $x=i_{1} \vee s_{1}$. As $x \leq i_{1} \vee s$ for $s \in(T \wedge J)$,

then $x \leq i_{1} \vee t$ when $s=t \in T$ and $x \leq i_{1} \vee j$ when $s=j \in J$.

This implies, $x \leq \mathrm{i}_{1} \vee \mathrm{t}$ and $\mathrm{x} \leq \mathrm{i}_{1} \vee \mathrm{j}$.

Then, $x \leq\left(i_{1} \vee t\right) \wedge\left(i_{1} \vee j\right)$. Which implies $x \in(I \vee T) \wedge(I \vee J)$.

Therefore, $(\mathrm{I} \vee(\mathrm{T} \wedge \mathrm{J})) \subseteq(\mathrm{I} \vee \mathrm{T}) \wedge(\mathrm{I} \vee \mathrm{J})$------(i)

Let $x \in(I \vee T) \wedge(I \vee J)$. Then $x \in(I \vee T)$ and $x \in(I \vee J)$.

This implies $x \leq i \vee t$ and $x \leq i \vee j$ for $i \in I, t \in T, j \in J$, as $T$ satisfies the condition. Then there exists $i_{1}$ and $t_{1}$ as

lower bounds of $i$ and $t$ respectively in $S$ such that $x=i_{1} \vee t_{1}$ and also $i_{1}$ and $j_{1}$ are lower bounds of $i$ and $j$ respectively in $S$ such that $x=i_{1} \vee j_{1}$. Thus $x=i_{1} \vee t_{1} \leq i_{1} \vee t$ and $x=i_{1} \vee j_{1} \leq i_{1} \vee j$. This means. $x \leq i_{1} \vee t$ and $x$ $\leq \mathrm{i}_{1} \vee \mathrm{j}$ which implies $\mathrm{x} \leq \mathrm{i}_{1}$ or $\mathrm{x} \leq \mathrm{t}$ and $\mathrm{x} \leq \mathrm{j}$. Then $\mathrm{x} \leq \mathrm{i}_{1} \vee(t \wedge \mathrm{j})$, so that $\mathrm{x} \in(\mathrm{I} \vee(\mathrm{T} \wedge \mathrm{J}))$.

Therefore, $(I \vee T) \wedge(I \vee J) \subseteq(I \vee(T \wedge J))$------(ii).

Then from (i) and (ii), we have $(\mathrm{I} \vee(\mathrm{T} \wedge \mathrm{J})) \leq(\mathrm{I} \vee \mathrm{T}) \wedge(\mathrm{I} \vee \mathrm{J})$.

Hence, an ideal $\mathrm{T}$ is simple if it satisfies the given relation.

1.18. Definition: An ideal D of 1-near semi lattice $\mathrm{S}$ is said to be distributive if and only if

$\mathrm{D} \vee(\mathrm{X} \wedge \mathrm{Y}) \leq(\mathrm{D} \vee \mathrm{X}) \wedge(\mathrm{D} \vee \mathrm{Y})$ for all ideals $\mathrm{X}, \mathrm{Y}$ of $\mathrm{S}$.

1.19. Definition: A binary relation $\theta_{\mathrm{D}}$ is said to be a congruence relation on $\mathrm{S}$ if (i) $\theta_{\mathrm{D}}$ is reflexive (ii) $\theta_{\mathrm{D}}$ is symmetric (iii) $\theta_{\mathrm{D}}$ is transitive and (iv) if $\mathrm{X} \equiv \mathrm{X}_{1}\left(\theta_{\mathrm{D}}\right)$ and $\mathrm{Y} \equiv \mathrm{Y}_{1}\left(\theta_{\mathrm{D}}\right)$ then,

$\mathrm{X} \wedge \mathrm{Y} \equiv \mathrm{X}_{1} \wedge \mathrm{Y}_{1}\left(\theta_{\mathrm{D}}\right)$ and $\mathrm{X} \vee \mathrm{Y} \equiv \mathrm{X}_{1} \vee \mathrm{Y}_{1}\left(\theta_{\mathrm{D}}\right)$.

$\S$ 2: Characterization theorem of simple ideal

2.1 Theorem: Let D be an ideal of al-near semi lattice S.

Then the following conditions are equivalent.

(i) D is simple ideal.

(ii) The binary relation $\theta_{D}$ on set of all ideals of $S(I(S))$ is defined by $X \equiv Y\left(\theta_{D}\right)$ if and only if $(X \vee Y) \wedge D_{1} \leq X \wedge$ $Y$ for some $\mathrm{D}_{1} \leq \mathrm{D}$ is a congruence relation.

(iii) $\mathrm{D}$ is distributive and for all $\mathrm{X}, \mathrm{Y} \in \mathrm{I}(\mathrm{S}), \mathrm{D} \wedge \mathrm{X} \leq \mathrm{D} \wedge \mathrm{Y}$; D DX $\leq \mathrm{D} \vee \mathrm{Y}$ implies $\mathrm{X} \leq \mathrm{Y}$.

Proof: To show that (i) implies (ii).

Suppose D is simple ideal.

To prove that $\theta_{\mathrm{D}}$ is reflexive, symmetric, $\mathrm{X} \equiv \mathrm{Y}\left(\theta_{\mathrm{D}}\right) \Leftrightarrow \mathrm{X} \vee \mathrm{Y} \equiv(\mathrm{X} \wedge \mathrm{Y})\left(\theta_{\mathrm{D}}\right)$.

If $X \leq Y \leq Z, X \equiv Y\left(\theta_{D}\right)$ and $Y \equiv Z\left(\theta_{D}\right) \Rightarrow X \equiv Z\left(\theta_{D}\right)$.

If $X \leq Y$ and $X \equiv Y\left(\theta_{D}\right)$, then $X \wedge Z \equiv Y \wedge Z\left(\theta_{D}\right)$ for all $X, Y, Z \in I(S)$.

(a) $\theta_{\mathrm{D}}$ is reflexive: By definition of binary relation $\theta_{\mathrm{D}}$,

$(X \vee X) \wedge D_{1} \leq X \wedge X$ for some $X=D_{1} \leq D$, implies $X \equiv X\left(\theta_{D}\right)$. Thus $\theta_{D}$ is reflexive.

(b) $\theta_{\mathrm{D}}$ is symmetric: Suppose $\mathrm{X} \equiv \mathrm{Y}\left(\theta_{\mathrm{D}}\right)$. Then $(\mathrm{X} \vee \mathrm{Y}) \wedge \mathrm{D}_{1} \leq \mathrm{X} \wedge \mathrm{Y}$ for some $\mathrm{D}_{1} \leq \mathrm{D}$.

This implies, $(\mathrm{Y} \vee \mathrm{X}) \wedge \mathrm{D}_{1} \leq \mathrm{Y} \wedge \mathrm{X}$ for some $\mathrm{D}_{1} \leq \mathrm{D}$. Which implies $\mathrm{Y} \equiv \mathrm{X}\left(\theta_{\mathrm{D}}\right)$.

Thus $\theta_{\mathrm{D}}$ is symmetric.

(c) Suppose $X \equiv Y\left(\theta_{D}\right)$.

Then $(X \vee Y) \wedge D_{1} \leq X \wedge Y$, for some

$\mathrm{D}_{1} \leq \mathrm{D} \Leftrightarrow((\mathrm{X} \vee \mathrm{Y}) \vee(\mathrm{X} \wedge \mathrm{Y})) \wedge \mathrm{D}_{1} \leq(\mathrm{X} \vee \mathrm{Y}) \wedge(\mathrm{X} \wedge \mathrm{Y})$ for some $\mathrm{D}_{1} \leq \mathrm{D}$,

bytaking $\mathrm{X}=\mathrm{X} \vee \mathrm{Y}, \mathrm{Y}=\mathrm{X} \wedge \mathrm{Y}$.

We have $(X \vee Y) \wedge D_{1} \leq X \wedge Y \Leftrightarrow X \vee Y \equiv(X \wedge Y)\left(\theta_{D}\right)$.

(d) Suppose $X \leq Y \leq Z$ and suppose $X \equiv Y\left(\theta_{D}\right)$ and $Y \equiv Z\left(\theta_{D}\right)$.

This implies $(\mathrm{X} \vee \mathrm{Y}) \wedge \mathrm{D}_{1} \leq \mathrm{X} \wedge \mathrm{Y}$ and $(\mathrm{Y} \vee \mathrm{Z}) \wedge \mathrm{D}_{2} \leq \mathrm{Y} \wedge \mathrm{Z}$ for some $\mathrm{D}_{1}, \mathrm{D}_{2} \leq \mathrm{D}$.

Let $\mathrm{Y} \wedge \mathrm{D}_{1}=\mathrm{X}$ and $\mathrm{Z} \wedge \mathrm{D}_{2}=\mathrm{Y}$ as $\mathrm{X} \leq \mathrm{Y} \leq \mathrm{Z}$. Now $(\mathrm{X} \wedge \mathrm{Z}) \wedge\left(\mathrm{D}_{1} \wedge \mathrm{D}_{2}\right) \leq \mathrm{X} \wedge \mathrm{Z} \wedge \mathrm{D}_{1} \wedge \mathrm{D}_{2} \leq \mathrm{X} \wedge \mathrm{Y} \wedge \mathrm{D}_{1} \leq \mathrm{X} \wedge \mathrm{X} \leq \mathrm{X}$

$=\mathrm{Y} \wedge \mathrm{D}_{1}=\mathrm{Z} \wedge \mathrm{D}_{1} \wedge \mathrm{D}_{2} \leq \mathrm{Z} \wedge\left(\mathrm{D}_{1} \wedge \mathrm{D}_{2}\right)$. And $(\mathrm{X} \vee \mathrm{Z}) \wedge\left(\mathrm{D}_{1} \wedge \mathrm{D}_{2}\right) \leq \mathrm{Z} \wedge\left(\mathrm{D}_{1} \wedge \mathrm{D}_{2}\right) \leq \mathrm{X} \wedge \mathrm{Z}$. Thus $\mathrm{X} \equiv \mathrm{Z}\left(\theta_{\mathrm{D}}\right)$. 
(e) Suppose $\mathrm{X} \leq \mathrm{Y}$ and $\mathrm{X} \equiv \mathrm{Y}\left(\theta_{\mathrm{D}}\right)$.

Then $(\mathrm{X} \vee \mathrm{Y}) \wedge \mathrm{D}_{1} \leq \mathrm{X} \wedge \mathrm{Y}$ for some $\mathrm{D}_{1} \leq \mathrm{D}$, since $\mathrm{X} \leq \mathrm{Y}, \mathrm{X} \wedge \mathrm{Z} \leq \mathrm{Y} \wedge \mathrm{Z}$.

This implies $((X \wedge Z) \vee(Y \wedge Z)) \wedge D_{1} \leq(X \wedge Z) \wedge(Y \wedge Z)$. Whish implies $X \wedge Z \equiv Y \wedge Z\left(\theta_{D}\right)$. Similarly if $X \leq Y$, then $X \vee Z \leq Y \vee Z$.This implies $((X \vee Z) \vee(Y \vee Z)) \wedge D_{1} \leq(X \vee Z) \wedge(Y \vee Z)$. Thus $(X \vee Z) \equiv(Y \vee Z)\left(\theta_{D}\right)$. Hence $\theta_{D}$ is a congruence relation.

To show that (ii) $\Rightarrow$ (iii).

Suppose the binary relation $\theta_{D}$ on $I(S)$ defined as $X \equiv Y\left(\theta_{D}\right)$ if and only if $(X \vee Y) \wedge D_{1} \leq X \wedge Y$ for some $D_{1} \leq D$ is a congruence relation. To prove that $\mathrm{D}$ is distributive ideal and for all $\mathrm{X}, \mathrm{Y}$ in $\mathrm{I}(\mathrm{S})$ if $\mathrm{D} \wedge \mathrm{X} \leq \mathrm{D} \wedge \mathrm{Y}$ and $\mathrm{D} \vee \mathrm{X}$

$\leq \mathrm{D} \vee \mathrm{Y}$. Then $\mathrm{X} \leq \mathrm{Y}$. First we prove that $\mathrm{D}$ is a distributive ideal.Thatis, $\mathrm{D} \vee(\mathrm{X} \wedge \mathrm{Y}) \leq(\mathrm{D} \vee \mathrm{X}) \wedge(\mathrm{D} \vee \mathrm{Y})$.

Consider $\mathrm{X} \wedge(\mathrm{X} \vee \mathrm{D}) \leq(\mathrm{X} \wedge(\mathrm{X} \vee \mathrm{D})) \wedge \mathrm{D} \leq \mathrm{X} \wedge \mathrm{D} \leq(\mathrm{X} \wedge \mathrm{X}) \wedge \mathrm{D} \leq \mathrm{X} \wedge(\mathrm{D} \wedge \mathrm{X})$. Thus $\mathrm{X} \equiv \mathrm{D} \vee \mathrm{X}\left(\theta_{\mathrm{D}}\right)$. Similarly $\mathrm{Y} \equiv$

$\operatorname{DVY}\left(\theta_{\mathrm{D}}\right)$.

Now consider $X \wedge Y \equiv[(D \vee X) \wedge(D \vee Y)]\left(\theta_{D}\right)$

This implies $(\mathrm{X} \wedge \mathrm{Y}) \vee[(\mathrm{D} \vee \mathrm{X}) \wedge(\mathrm{D} \vee \mathrm{Y})] \leq((\mathrm{X} \wedge \mathrm{Y}) \wedge[(\mathrm{D} \vee \mathrm{X}) \wedge(\mathrm{D} \vee \mathrm{Y})]) \wedge \mathrm{D}$.

Which implies $(\mathrm{X} \wedge \mathrm{Y}) \vee \mathrm{D} \leq[(\mathrm{D} \vee \mathrm{X}) \wedge(\mathrm{D} \vee \mathrm{Y})][\operatorname{as}(\mathrm{D} \vee \mathrm{X}) \wedge(\mathrm{D} \vee \mathrm{Y}) \leq \mathrm{D} \vee \mathrm{D}=\mathrm{D}]$.

Thus $\mathrm{D} \vee(\mathrm{X} \wedge \mathrm{Y}) \leq(\mathrm{D} \vee \mathrm{X}) \wedge(\mathrm{D} \vee \mathrm{Y})$. Hence $\mathrm{D}$ is distributive ideal. Suppose $\mathrm{D} \wedge \mathrm{X} \leq \mathrm{D} \wedge \mathrm{Y}$ and $\mathrm{D} \vee \mathrm{X} \leq \mathrm{D} \vee \mathrm{Y}$ and since $\mathrm{X} \equiv(\mathrm{D} \vee \mathrm{X})\left(\theta_{\mathrm{D}}\right)$ and $\mathrm{Y} \equiv(\mathrm{D} \vee \mathrm{Y})\left(\theta_{\mathrm{D}}\right)$.

Thisimplies $X \vee Y \equiv[(D \wedge X) \vee(D \wedge Y)]\left(\theta_{D}\right)=[(D \wedge X) \vee(D \wedge X)]\left(\theta_{D}\right)($ as $D \wedge X=D \wedge Y)=D \wedge X\left(\theta_{D}\right) \equiv X$. Thus $\mathrm{X} \vee \mathrm{Y} \equiv \mathrm{X}\left(\theta_{\mathrm{D}}\right)$. Now $((\mathrm{X} \vee \mathrm{Y}) \vee \mathrm{X}) \wedge \mathrm{D}_{1} \leq(\mathrm{X} \vee \mathrm{Y}) \wedge \mathrm{X} \leq \mathrm{X}$.

This implies $(X \vee Y) \wedge D_{1} \leq X$----- (i). Also by relation we have $(X \vee Y) \wedge D_{1} \leq X \wedge Y$-----(ii), Thus we have $X \wedge Y$ $=\mathrm{X}$, implies $\mathrm{X} \leq \mathrm{Y}$.

To show that (iii) $\Rightarrow$ (i):

Suppose $\mathrm{D}$ is distributive and for $\mathrm{D} \wedge \mathrm{X} \leq \mathrm{D} \wedge \mathrm{Y}$ and $\mathrm{D} \vee \mathrm{X} \leq \mathrm{D} \vee \mathrm{Y}$ implies $\mathrm{X} \leq \mathrm{Y}$.

Now to prove that $\mathrm{D}$ is simple ideal.That is, $\mathrm{X} \vee(\mathrm{D} \wedge \mathrm{Y})=(\mathrm{X} \vee \mathrm{D}) \wedge(\mathrm{X} \vee \mathrm{Y})$.

Let $\mathrm{A}=\mathrm{X} \vee(\mathrm{D} \wedge \mathrm{Y})$ and $\mathrm{B}=(\mathrm{X} \vee \mathrm{D}) \wedge(\mathrm{X} \vee \mathrm{Y})$.

Then we prove that if $\mathrm{D} \wedge \mathrm{A} \leq \mathrm{D} \wedge \mathrm{B}$ and $\mathrm{D} \vee \mathrm{A} \leq \mathrm{D} \vee \mathrm{B}$.

Then by condition $\mathrm{A} \leq \mathrm{B}$. Since $\mathrm{D} \vee \mathrm{X} \leq \mathrm{D} \vee[\mathrm{X} \vee(\mathrm{D} \wedge \mathrm{Y})]=\mathrm{D} \vee \mathrm{A}$.

Thus DV $\mathrm{X} \leq \mathrm{D} \vee \mathrm{A} \ldots \ldots(\mathrm{I})$

Now $\mathrm{D} \vee \mathrm{B}=\mathrm{D} \vee[(\mathrm{X} \vee \mathrm{D}) \wedge(\mathrm{X} \vee \mathrm{Y})]=\mathrm{D} \vee[(\mathrm{D} \vee \mathrm{X}) \wedge(\mathrm{X} \vee \mathrm{Y})] \leq \mathrm{D} \vee[\mathrm{D} \vee \mathrm{X}]=\mathrm{D} \vee \mathrm{X}$. Therefore $\mathrm{D} \vee \mathrm{B} \leq \mathrm{D} \vee \mathrm{X}$ .....(II).

Hence form (I) and (II) we have DVA $\leq$ DV B.

Now consider $\mathrm{D} \wedge \mathrm{B}=$

$\mathrm{D} \wedge[(\mathrm{X} \vee \mathrm{D}) \wedge(\mathrm{X} \vee \mathrm{Y})] \geq \mathrm{D} \wedge[(\mathrm{D} \vee \mathrm{B}) \wedge(\mathrm{X} \vee \mathrm{Y})] \geq \mathrm{D} \wedge[(\mathrm{D} \vee \mathrm{A}) \wedge(\mathrm{X} \vee \mathrm{Y})] \geq$

$\mathrm{D} \wedge[(\mathrm{D} \vee \mathrm{A}) \wedge(\mathrm{X} \vee(\mathrm{D} \wedge \mathrm{Y})]=\mathrm{D} \wedge(\mathrm{D} \vee \mathrm{A}) \wedge[(\mathrm{X} \vee(\mathrm{D} \wedge \mathrm{Y})]=\mathrm{D} \wedge[(\mathrm{X} \vee(\mathrm{D} \wedge \mathrm{Y})]=\mathrm{D} \wedge \mathrm{A}$

Therefore $\mathrm{D} \wedge \mathrm{B} \geq \mathrm{D} \wedge \mathrm{A}$ (or) $\mathrm{D} \wedge \mathrm{A} \leq \mathrm{D} \wedge \mathrm{B}$.

Therefore for $\mathrm{D} \vee \mathrm{A} \leq \mathrm{D} \vee \mathrm{B}$ and $\mathrm{D} \wedge \mathrm{A} \leq \mathrm{D} \wedge \mathrm{B}$ we have $\mathrm{A} \leq \mathrm{B}$.

Hence $\mathrm{D}$ is simple ideal of $\mathrm{S}$.

2.2 Theorem: The necessary and sufficient condition for a distributive ideal $\mathrm{D}$ to be simple in a 1-near semilattice $\mathrm{S}$ is that $\mathrm{D} \wedge \mathrm{X} \leq \mathrm{D} \wedge \mathrm{Y}$ and $\mathrm{D} \vee \mathrm{X} \leq \mathrm{D} \vee \mathrm{Y}$ for all ideals $\mathrm{X}, \mathrm{Y}$ in $\mathrm{I}(\mathrm{S})$, implies $\mathrm{X} \leq \mathrm{Y}$.

Proof: Suppose a distributive ideal D of S satisfies the condition that $\mathrm{D} \wedge \mathrm{X} \leq \mathrm{D} \wedge \mathrm{Y}$ and $\mathrm{D} \vee \mathrm{X} \leq \mathrm{D} \vee \mathrm{Y}$ for all ideals $\mathrm{X}, \mathrm{Y}$ in $\mathrm{I}(\mathrm{S})$. This implies $\mathrm{X} \leq \mathrm{Y}$. Then by characterization theorem of simple ideal, $\mathrm{D}$ is simple ideal of $\mathrm{S}$. Conversely suppose that $\mathrm{D}$ is a simple ideal of $\mathrm{S}$.

If we define a binary relation $\theta_{D}$ as $X \equiv Y\left(\theta_{D}\right)$ if and only if $(X \vee Y) \wedge D_{1} \leq X \wedge Y$ for some $D_{1} \leq D$ is a congruence relation. Then by the theorem of characterization of simple ideal we have $\mathrm{D}$ is distributive and $\mathrm{D} \wedge \mathrm{X} \leq \mathrm{D} \wedge \mathrm{Y}$ and DVX $\leq$ DVY for all ideals $\mathrm{X}, \mathrm{Y}$ in $\mathrm{I}(\mathrm{S})$, implies $\mathrm{X} \leq \mathrm{Y}$.

2.3 Theorem: An element s of 1-near semilattice $\mathrm{S}$ is simple if and only if (i) $\mathrm{s}$ is distributive and (ii) $\mathrm{s}$ is modular.

Proof: Suppose an element s in 1-near semilattice S be simple. Since every simple element of 1-near semilattice is a distributive element of $\mathrm{S}$, then $\mathrm{s}$ is a distributive element.

(ii) To prove that $\mathrm{s}$ is modular element. Let $\mathrm{y} \leq \mathrm{s} \vee \mathrm{x}$ with $\mathrm{x} \leq \mathrm{y}$, as $\mathrm{s}$ is simple. Then there exists $\mathrm{s}_{1}$ and $\mathrm{x}_{1}$ are lower bounds of sand $x$ in $S$ such that $y=s_{1} \vee x_{1}$.

Since $\mathrm{x} \leq \mathrm{y}$, we have $\mathrm{y}=\mathrm{x} \vee \mathrm{y}=\mathrm{x} \vee \mathrm{s}_{1} \vee \mathrm{x}_{1}=\mathrm{s}_{1} \vee \mathrm{x} \vee \mathrm{x}_{1}=\mathrm{s}_{1} \vee \mathrm{x}$.

Therefore $y=s_{1} \vee x$. Hence $s$ is modular element.

Conversely suppose that an element $\mathrm{s}$ is both distributive and modular in $\mathrm{S}$.

Now to prove that $\mathrm{s}$ is simple element. 
Let $\mathrm{y} \leq \mathrm{sV} \mathrm{x}$ as $\mathrm{s}$ is distributive element and as $\mathrm{y} \leq \mathrm{s} \vee \mathrm{y}$. Then there exists a lower bound $\mathrm{t}$ of $\mathrm{x}$ and $\mathrm{y}$ in $\mathrm{S}$ such that $\mathrm{y} \leq \mathrm{s} \vee \mathrm{t}$ and since $\mathrm{s}$ is modular element, $\mathrm{s}_{1}$ is lower bound of $\mathrm{s}$ in $\mathrm{S}$ such that $\mathrm{y}=\mathrm{s}_{1} \mathrm{Vt}$. Thus for $\mathrm{y} \leq \mathrm{sV} \mathrm{x}$, there exists $\mathrm{s}_{1}$ and $\mathrm{t}$ are lower bounds of $\mathrm{s}$ and $\mathrm{x}$ in $\mathrm{S}$ such that $\mathrm{y}=\mathrm{s}_{1} \mathrm{Vt}$. Hence $\mathrm{s}$ is simple element of $\mathrm{S}$.

2.4 Theorem: If 1-nearsemilattice is modular, then every distributive element is a simple element. Proof: Suppose $\mathrm{S}$ is 1-near semilattice which is modular.

Then for $\mathrm{x}, \mathrm{y}, \mathrm{z}$ in $\mathrm{S}$ for $\mathrm{z} \leq \mathrm{x} \leq \mathrm{yV} \mathrm{z}$, then there exists $\mathrm{y}_{1}$ a lower bound of yin $\mathrm{S}$ such that $\mathrm{x}=\mathrm{y}_{1} \vee \mathrm{z}$. Let an element $\mathrm{s}$ in $\mathrm{S}$ be distributive. Let $\mathrm{x} \leq \mathrm{s} \vee \mathrm{y}$ and as $\mathrm{x} \leq \mathrm{s} \vee \mathrm{x}$. There exists a lower bound $\mathrm{z}$ for $\mathrm{x}$ and $y$ such that $x \leq s \vee z$. Since $S$ is modular, every element of $S$ is modular. Thus $\mathrm{s}$ in $\mathrm{S}$ is modular. Hence there is $\mathrm{s}_{1} \leq \mathrm{s}$ such that $\mathrm{x}=\mathrm{s}_{1} \vee \mathrm{y}_{1}$. Hence $\mathrm{s}$ is simple element.

\section{IV.CONCLUSION}

This manuscript initiates meticulously the concept 1-near semilattice and its modularity, distributivity, simple element, modular element, ideal, simple ideal, modular ideal, distributive element. It is perceived that every element of a modular 1-near semilattice is modular and if every element of al-near semilattice is modular, then it is a modular 1-near semilattice. It is remarked that an element of 1-near semilattice is modular if and only if the set of its lower bounds is a modular ideal of S. It is ascertained that every simple element of l-near semilattice $\mathrm{S}$ is a distributive element of S. It is observed that the least upper bound of any two simple elements of a 1- near semilattice is also a simple element.Moreover, various properties of ideals and congrurences in 1-near semilattice have been studied. It is noted that an element of an 1-near semilattice is simple if and only if it is

distributive and modular. Finally it is concluded that if an 1-nearsemilattice is modular, then every distributive element is a simple element.

\section{REFERENCES}

[1] Gratzer G and Schmidit,E.T. Standard ideals in lattices, Acta Math, Acad.Sci.Hungar.Vol.12,P.P.17-86.,1961.

[2] Hossian,M.A. Distributive filters of a meet semi lattice directed above, Jahangirnagar University journal of science, Vol.27, P.P 291298,2004.

[3] Malliab,C and Bhatta,S.P. A generalization of distributive ideals to convex sublattice,Acta.Math.Hungar,Vol.48(1-2)P.P.73-78,1986.

[4] Ramana Murthy, P.V and Ramam,V. Permutability of Distributive congruence relations in join semi lattice directed below, Math.Slovacca Vol.35,P.P 43-49, 1985.

[5] VasanthaKandasamy W.B., A new type of product on lattice- Near semilattice, Vikram mathematical journal, Vol.13,PP.23-27,1993. 